\title{
Management of postoperative delirium for geriatric patients with hip fracture: A quasi-experimental study
}

\author{
Lap Fung Tsang ${ }^{* 1}$, Wing Yin Yiu ${ }^{2}$, Wing Hang Kwok ${ }^{2}$, Chi Chung Tse ${ }^{2}$, Sze Wing $\mathrm{Ng}^{2}$, Kwok Keung Chu ${ }^{2}$, Wing \\ Sing Wong ${ }^{2}$, Ming Kai Wong ${ }^{2}$, Tim Hung ${ }^{2}$, Ching Yan Kong ${ }^{2}$, Sheung Chi Tong ${ }^{2}$, So Yuen Alice Sham ${ }^{1}$, Chi Wai \\ Chan $^{2}$ \\ ${ }^{1}$ Nursing Services Division, United Christian Hospital, Hong Kong \\ ${ }^{2}$ Department of Orthopaedics \& Traumatology, United Christian Hospital, Hong Kong
}

Received: January 21, 2014

DOI: $10.5430 /$ cns.v3n2p40
Accepted: December 16, 2014 Online Published: January 4, 2015

URL: http://dx.doi.org/10.5430/cns.v3n2p40

\begin{abstract}
Introduction: Delirium is one of the postoperative complications in the group of geriatric patients with hip fracture. A variety of measures were addressed on prevention of postoperative delirium but the prevalence of it remains high over the world. Postoperative delirium surely disturbs rehabilitative processes of patients and adds emotional burden to nurses. As a result, an effective postoperative delirium management is important to this group of patients and healthcare providers. Aim: This study was to determine the effectiveness of the modified Risk Assessment and Management of Postoperative delirium (RAMP) care plan on the management of delirious patients receiving hip fractures operation in two comparable groups.
\end{abstract}

Methods: A quasi-experimental sampling using a time-series design was carried out to assign subjects to the conventional and protocol care group according to the inclusion and exclusion criteria. The incident rate of postoperative delirium was determined. The length of hospital stay, the duration of the postoperative delirium and the mean of delirious day after operation in the two groups were compared using ANOVA analysis.

Results: Of 303 participants, 62 subjects were eligible for conventional group and 49 subjects were eligible for protocol group. The duration of patients developing delirium postoperatively in the protocol care group (mean days $=2.33$ ) was significantly different from that in the conventional care group (mean days $=3.5$ ). Further, the length of stay which was recorded from patients receiving operation to discharge or transfer was found significantly different between the conventional group (9.06 days) and the protocol group (8.17 days). The mean days of the development of delirium after operation in the conventional care group was 2.13 whereas that in the protocol care group were 1.17 .

Conclusion: The RAMP care plan was proved its effectiveness on shortening the duration of postoperative delirium by 1.17 days. In spite of the inspired results, it was suggested that the modified RAMP care plan should be used for screening and assessment before patients receiving hip surgery.

Key Words: Postoperative delirium, Management, Predictive factors, Prevention, RAMP care plan, Protocol

\section{Introduction}

Delirium is one of the postoperative complications in the group of geriatric patients with hip fracture. It also can lead to an increased risk of complications. ${ }^{[1]}$ Among a variety of measuring methods to detect delirium, it accounts for $9.0 \%$ to $65.0 \%$ of geriatric patients after hip fracture. ${ }^{[2,3]}$ Obvi-

\footnotetext{
${ }^{*}$ Correspondence: Lap Fung Tsang; Email: tsanlf1@ @a.org.hk; Address: Room 250, 2/F, Block F, 130 Hip Wo Street, UCH, KLN, Kwun Tong, Hong Kong.
} 
ously, postoperative delirium can affect successful rehabilitation because it takes time to reverse symptoms of mental status and resume physical rehabilitative program.

As of 2009, more than 250,000 older Americans were hospitalized with hip fracture yearly, leading to direct medical costs in excess of ten billion US dollars per year. ${ }^{[4]}$ In Hong Kong, the total treatment cost for patients with hip fracture was HK\$ 150 million in 1995. ${ }^{[5]}$ Other reported that the direct medical care costs of hip fracture increased by $4.5 \%$ from 2001 to 2004 in Korea. ${ }^{[6]}$ Cost spent on medical treatments can burden the whole healthcare system along with expectedly increasing life expectancy throughout the globe. Reducing complications and shortening hospital stay would be our challenges in the group of patients.

\subsection{Background}

After the last two decades, preventive intervention programs for patients with hip fracture, early recognition and delirium management have been developed and shown to be effective. ${ }^{[7-9]}$ A study demonstrated an effectively preventive protocol to deal with postoperative delirium in an orthopaedic ward was developed. ${ }^{[10]}$ The Risk Assessment and Management of Postoperative delirium (RAMP) care plan involves the part of risk assessment and preventive measures and it is suggested to start implementation as early as possible when patient admitted upon operation. Moreover, it is so effective and paramount to return one's mental status to normal. However there is a paucity of protocol about the management of postoperative delirium. One of the reasons is that the preventive interventions are more important than the measures given to delirious patients. Also there is no literature describing its difficulties when implementing protocol or care plan for postoperative delirious patients.

\subsection{Aim}

This study was to determine the effectiveness of the RAMP care plan on the management of delirious patients receiving hip fractures operation in the two comparable groups.

\section{Methods}

\subsection{Study design}

A quasi-experimental sampling using a time-series design was carried out to allocate subjects to the conventional and protocol care group according to the inclusion and exclusion criteria. This study was undertaken in 3 acute and 1 rehabilitative orthopaedic wards, with a total 154 beds, of a local district hospital, United Christian Hospital in Hong Kong. Subjects were consecutive allocated to the conventional group from April to June 2013 and to the experimental group from July to October 2013. Nurses need one month to get used to the RAMP care plan and the data collected in July were not included. The first author was responsible for data collection and data analysis.

\subsubsection{Inclusion criteria}

Patients who aged 60 or above admitted for hip fracture surgery and who could communicate in Cantonese or English were recruited. Written consent was sought by doctors or investigators. Surgeons based on a Mini-Mental State Examination (MMSE) test result or cognitive assessments performed by Occupational therapists to judge if demented patients were appropriate to participate within the study. Psychiatric physicians were also referred to assess its appropriateness to give consent and understand the operation and the parameters of the study.

\subsubsection{Exclusion criteria}

Patient who could not demonstrate capacity to understand and reason through reasonable risks/benefits for surgery or who could not communicate in Cantonese or English was excluded. Patient was excluded if developing delirium before surgery.

\subsection{Sample size calculation}

A total of 90 patients will enter this two-treatment paralleldesign study. The probability is 80 percent that the study will detect a treatment difference at a two-sided 0.05 significance level, if the true difference between treatments is 0.598 times the standard deviation. ${ }^{[11]}$ This means that there is $80 \%$ likelihood that the study yields statistically significant effects this concluding that the mean duration difference of postoperative delirium day for usual care group could be compared to the modified protocol group, if the true difference between groups is 0.598 times the standard deviation. Data were treated with the principle of intention to treat for analysis.

\subsection{The conventional care}

The conventional care is referred to the usual practice that nurses manage patients with postoperative delirium without any standard care plan. Orthopaedic surgeon generally ordered restraints to prevent patients' fall or violence due to aggressive behavior of patients. They seldom sought for opinion from other specialties like Geriatric medical physician. Furthermore, no immediate action such as investigation of underlying cause was taken by surgeon. On the other hand, haloperidol is one of the medications commonly prescribed to control symptoms of delirium but there was no standard dose or frequency when prescribed. Nurses did not have a systematic assessment and care plan to provide appropriate care to delirious patients. 


\subsection{The protocol care}

\subsubsection{Modified RAMP care plan}

The RAMP care plan is used for the prediction, prevention and management on postoperative delirium in geriatric patients. ${ }^{[10]}$ It is adapted to use to manage delirious patients after the hip surgery in this study. Some risk factors identified in the RAMP care plan are erased because they are not appropriate to assess if patients developed to postoperative delirium. For example, the Mini-mental state examination test for cognitive impairment is eliminated because delirious patient is not cooperative.

The National Clinical Guideline Centre (NCGC) recommended that oral haloperidol is considered for delirious patients with $0.5 \mathrm{mg}$ every 8 hours for 1 week when necessary. ${ }^{[12]}$ However, the said dose is not appropriate because it is relatively a heavy dose for eastern patients as discussed with local geriatric doctors. This is because the body size from western people is generally bigger than that of eastern. In view of this, the dose and frequency of haloperidol is adjusted to $0.25 \mathrm{mg}$ orally when necessary, following $0.25 \mathrm{mg}$ nocte or twice daily for one week when necessary.

\subsubsection{Compare and contrast the interventions of the con- ventional and modified protocol group}

Physical restraint is not recommended but still needs to consider in both groups if necessary. The common nursing practices include monitoring of intake and output of patient, reviewing of poly-pharmacy, dehydration management, encouragement of doing exercise, pain management, hypoxia management, urinary tract infection or upper respiratory tract infection management and continence management.

The major differences between the conventional and protocol care group are outlined in Table 1. In the modified protocol care group, nurses carry out the Confusion Assessment Method (CAM) to rule out delirious patients preoperatively. Patients are assessed with MMSE by occupational therapists and nurses before operation. A standard assessment covering mental and behavioral, sensory, electrolyte disturbance, immobility, physiological and infection is conducted if the patient developed postoperative delirium. Meanwhile, visual assessment with Near Visual Test (NVT) card and malnutrition assessment with Malnutrition Screening Tool (MST) are carried out by nurses. An educational pamphlet developed in the Tsang's study is given to patients and carers for information. As a result, nurses become more proactive in the management of delirious patients according to the modified protocol care. ${ }^{[13]}$

\subsection{Outcome measures}

The following instruments were used to diagnose patients as delirium after surgery: CAM. The CAM was developed to determine the incident of postoperative delirium. ${ }^{[14]}$ Per- mission was sought from the authors to use CAM in this study. The CAM algorithm is a reliable and valid diagnostic instrument. ${ }^{[15,16]}$ The CAM assesses on the following 3 criteria: acute onset and fluctuating course, inattention and disorganized thinking or altered level of consciousness. ${ }^{[17]}$ The CAM was performed on delirious patient by trained nurses in the evening daily in the protocol group until their mental status resumed to normal. Surgeons also need to assess patients with the CAM every morning. In the conventional group, nurses call orthopaedic surgeon to manage the delirious patients whenever the signs and symptoms of delirium appear.

\subsection{Ethical considerations}

The participants were given an information sheet wherein objectives, expectations, management of the study were explained. Confidentiality was upheld and a written consent was sought. The study was approved by the Research Ethics Committee (Kowloon Central/ Kowloon East) (Ethical approval: KC/KE-13-0038/ER-5). There was no risk arisen throughout the study.

\subsection{Data analyses}

All data analyses were analyzed using SPSS, version 19.0 (SPSS Inc., Chicago, IL). The prevalence rate of postoperative delirium was evaluated throughout the study. The Chi-square test was performed to test for differences in the effectiveness between the modified protocol and usual care. The unpaired t-test followed by ANOVA analysis was used to test the difference of the duration of postoperative delirium between the modified protocol and conventional care group. Baseline characteristics of the participants were described. Adverse effect of drug was reported if any.

\section{Results}

A consecutive sample of 303 patients with hip fractures was initially included in this study at the two study phases: (1) April to June 2013, and (2) August to October 2013 (see Figure 1). Of these, 111 patients completed within the study (62 in conventional group and 49 in protocol group). 95 participants were not included due to refusing, severe dementia, communication problems, change of mental status after consent signed upon surgery and missing cases.

The mean age of participants was 79.71 years old (protocol group mean age: 80.09 years and conventional group 79.32 years). Age ranged from 60 to 94 years old. 66 participants were female and 45 were male. The incident rate of postoperative delirium in terms of gender did not show significant difference in the conventional and protocol care groups $\left(\chi^{2}\right.$ $=3.17 \mathrm{df}=1, p>.05)$. Cognitive impairment was found to be significant difference in patients who developed postoperative delirium under conventional group $\left(\chi^{2}=10.44\right.$, $\mathrm{df}$ $=2, p=.001$ ) whereas it was not significant difference in 
patients who developed postoperative delirium under protocol care $\left(\chi^{2}=0.73\right.$, df $\left.=1, p>0.05\right)$. The mean days of patients developing delirium after surgery in the protocol care group were 2.33 days which was significantly different from 3.5 mean days of the conventional care group $(\mathrm{t}[18]=3.8, p=.001)$. Further, the length of stay which was recorded from patients receiving operation to discharge or transfer was found significant difference between the two care groups $(\mathrm{t}[108]=15.3, p<.001)$. The mean days of the development of postoperative delirium in the conventional care group was 2.13 whereas that in the protocol care group was $1.17(\mathrm{t}[20]=1.34, p>.05)$ (see Table 2).

Table 1: Difference between conventional care and protocol care

\begin{tabular}{|c|c|}
\hline Conventional Care & Protocol Care \\
\hline No Delirium screening assessment by nurses & Conduct CAM assessment tool by doctors and nurses \\
\hline Not all patients indicated for MMSE after admission & $\begin{array}{l}\text { All patients are assessed with MMSE by Occupational therapists and } \\
\text { nurses before operation }\end{array}$ \\
\hline $\begin{array}{l}\text { No specific risk assessments method to manage the } \\
\text { development of delirium }\end{array}$ & $\begin{array}{l}\text { A systematic assessment including mental \& behavioral, sensory, } \\
\text { electrolyte disturbance, immobility, physiological, and infection is } \\
\text { assessed if developing postoperative delirium }\end{array}$ \\
\hline Without objective constipation assessment & Constipation assessment with evidence interventions \\
\hline Assess visual impairment without assessment tool & Assess visual impairment with Near Visual Test card \\
\hline No care plan to manage delirious patients & $\begin{array}{l}\text { A RAMP care plan involves a variety of interventions to guide nurse } \\
\text { to provide interventions to delirious patients }\end{array}$ \\
\hline No objective assessment on malnutrition & Assess malnutrition with MST assessment tool \\
\hline $\begin{array}{l}\text { No consistent medication prescription by doctors for } \\
\text { delirious patients }\end{array}$ & $\begin{array}{l}\text { A suggested prescription formula with evidence to doctors in the care } \\
\text { plan }\end{array}$ \\
\hline No educational pamphlet regarding delirium management & $\begin{array}{l}\text { A pamphlet regarding delirium management is given to carers of } \\
\text { delirious patients }\end{array}$ \\
\hline $\begin{array}{l}\text { Address on caring of complications associated with } \\
\text { symptoms of delirium }\end{array}$ & $\begin{array}{l}\text { Address on risk factors and its interventions of delirium (more } \\
\text { proactive) }\end{array}$ \\
\hline
\end{tabular}

\section{Discussion}

Delirium is revisable, preventable and treatable if healthcare provider recognizes early. ${ }^{[18]}$ Early reverse of symptom of delirium depends on timely effective management. Nurses have been guided with the modified RAMP care plan to manage patients developing postoperative delirium. According to the modified protocol, surgeons need to prescribe medication accordingly at the early phase if patient developed postoperative delirium. In this study, most of them did not comply with it because they are necessary to rule out the underlying causes of patients due to sudden change of behavior and mental status according to the protocol. Generally, it takes time to arrange the computed tomography (CT) brain scan that is the unique scientific method to accurately rule out other underlying cause. Thus, surgeons are difficult to prescribe medications within twenty-four hours.

For the frequency of using the CAM to detect delirium postoperatively, it was suggested performing twice daily as reported by a study. ${ }^{[19]}$ However, nurses only performed daily in the evening whereas doctors performed it every morning.

Indeed, nurses play a crucial role in ensuring optimal outcomes for delirious patients. ${ }^{[20]}$ In this study, some of the risk factors assessment like alcohol abuse and malnutrition were impossible to perform when patients were confusing because they were unable to communicate and uncooperative.

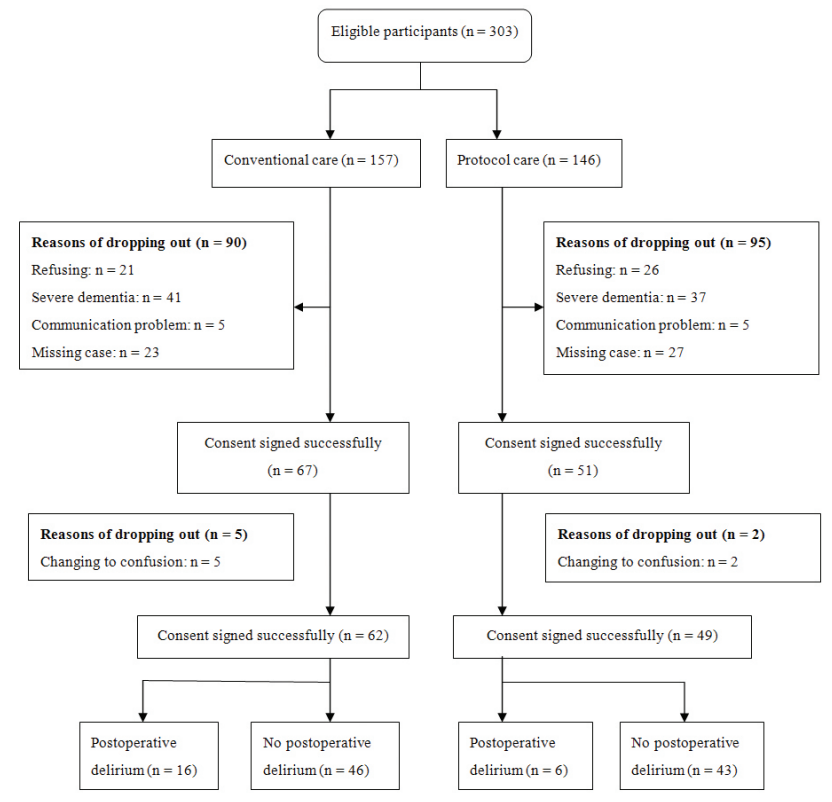

Figure 1: Number of subjects developing postoperative delirium in conventional and protocol care 
Table 2: Demographic and characteristic data of participants between control and conventional groups

\begin{tabular}{|c|c|c|c|c|c|}
\hline \multirow[b]{2}{*}{ Characteristics } & \multicolumn{2}{|c|}{ Conventional group } & \multicolumn{2}{|c|}{ Protocol group } & \multirow[b]{2}{*}{$P$ value } \\
\hline & $\begin{array}{l}\text { Postoperative } \\
\text { delirium }\end{array}$ & $\begin{array}{l}\text { No postoperative } \\
\text { delirium }\end{array}$ & $\begin{array}{l}\text { Postoperative } \\
\text { delirium }\end{array}$ & $\begin{array}{l}\text { No postoperative } \\
\text { delirium }\end{array}$ & \\
\hline \multicolumn{6}{|l|}{ Gender (n) } \\
\hline Male & 8 & 23 & 4 & 10 & -- \\
\hline Female & 8 & 23 & 2 & 33 & -- \\
\hline Mean Age (years old) & 79.62 & 79.02 & 80.67 & 79.51 & -- \\
\hline \multicolumn{6}{|l|}{ Pre-operative cognitive assessment (n) } \\
\hline Cognitive impairment & 9 & 7 & 2 & 8 & -- \\
\hline No cognitive impairment & 7 & 39 & 4 & 35 & -- \\
\hline Total & 16 & 48 & 6 & 43 & -- \\
\hline Fall (n) & 0 & 0 & 0 & 0 & -- \\
\hline Pressure ulcer (n) & 0 & 0 & 0 & 0 & -- \\
\hline $\begin{array}{l}\text { Day of the development of delirium } \\
\text { postoperatively (mean day) }\end{array}$ & 2.13 & & 1.17 & & $>.05$ \\
\hline Duration of delirium lasting for (mean day) & 3.5 & & 2.33 & & $=.001$ \\
\hline
\end{tabular}

Nevertheless it does not mean that nurses do not need to communicate with delirious patients. Conversely, nurses can orientate delirious patients regularly. Through the patient orientation to time, place and person regularly, and early mobilization and rehabilitation, delirious patients can be re-orientated earlier from confusion. ${ }^{[21]}$

One study showed that the involvement of a geriatrician in the perioperative care of patients with hip fracture reduced the risk of delirium by $40 \%{ }^{[8]}$ It also found that early detection and prevention of delirium were possible according to observation focusing on the evaluation of cognitive impairment of the patients by trained nurses. ${ }^{[22]}$ These studies focused on early detection and prevention of the development of postoperative delirium. However, there is a paucity of literature to exanimate the effectiveness of postoperative delirium management to shorten the duration of patients with postoperative delirium. This study is a pioneer one to highlight a well-developed modified RAMP care plan that can reduce the length of stay and the duration of postoperative delirium effectively. This study also emphasizes the importance of a proactive management (prediction and prevention) that is much better than a reactive management (cure) to manage post-operative delirium. The British Geriatric Society emphasized initial management strategies through ongoing assessment and intervention as well as the symptoms of the identified risk. ${ }^{[23]}$ Therefore, nurses should not only focus on the management of delirious patients but also need to predict and prevent from it upon surgery. The modified RAMP care plan has guided nurses to identify and manage any possible underlying cause of postoperative delirium.

\section{Study limitations}

The authors were facing several methodological challenges in this study. The prevalence rate of postoperative delir- ium in the conventional and protocol care groups were only $25.8 \%$ and $12.2 \%$ respectively and were not significantly different from each other. According to the prevalence rate in the previous study conducted in $2010,{ }^{[24]}$ postoperative delirium was found in $21 \%$. In addition, single-blind research is not possible to apply in this study because patients have every right to know throughout the study.

The Hawthorne effect is necessarily concerned in this study because nurses might predominantly provide preventive interventions to patients as couples of briefing sessions about the application of the modified RAMP care plan were held during the conventional group, in turn, influencing to the result.

\section{Conclusion}

The modified RAMP care plan was proved its effectiveness on reducing the duration of postoperative delirium development by 1.17 days. In spite of the inspired results, it was suggested that the modified RAMP care plan should be used for screening and assessment before patients receiving hip surgery. A proactive management (prediction and prevention) is much better than a reactive management (cure) to manage post-operative delirium.

\section{Acknowledgements}

We extend our gratitude to the Occupational Therapy Department for assistance in the MMSE test, to Dr. Inouye SK for giving permission to use CAM in this study, to Dr. Leung Man Fuk (Chief of Service of M\&G) for his invaluable opinion, and to all nurses of the department of Orthopaedics \& Traumatology in the United Christian Hospital for participating in the study. I would like to take this opportunity to thank Dr. Chan Chi Wai (Chief of Service of O\&T), 
Ms. Kong Ching Yan (Department Operations Manager of O\&T) and Ms. Hung Tim (the former Department Operations Manager of O\&T) for their full support in this study.

\section{Conflicts of Interest Disclosure}

\section{References}

[1] Bitsch M, Foss N, Kristensen B, Kehlet H. Pathogenesis and management strategies for postoperative delirium after hip fracture: a review. Acta Orthop Scand. 2004; 75(4): 378-89. PMid:15370579. http://dx.doi.org/10.1080/00016470410001123

[2] Sorensen DG, Wilblad K. Acute confusional states in patients undergoing hip surgery. J Gerontol. 2000; 46: 36-43. http://dx.doi . org/10.1159/000022131

[3] White JE, Khan WS, Smitham PJ. Perioperative implications of surgery in elderly patients with hip fractures: an evidence based review. JPP. 2011; 21(6): 192-7. PMid:21823308.

[4] Cummings SR, Rubin SM, Black D. The future of hip fractures in the United States. Clin Orthop Relat Res. 1990; 252: 163-6. PMid:2302881.

[5] The Working Group for Formulating Clinical Management Guidelines for Osteoporosis in Hong Kong. Clinical management guidelines for osteoporosis in Hong Kong. Hong Kong Med J. 1998; 4: 423-31.

[6] Lim S, Koo BK, Lee EJ, Park JH, Kim MH, Shin KH, et al. Incidence of hip fractures in Korea. JBMM. 2008; 26: 4005. PMid:18600408. http://dx.doi.org/10.1007/s00774-007 -0835-z

[7] Gustafson Y, Brannstrom B, Berggren D, Ragnarsson JI, Sigaard J, Bucht $\mathrm{G}$, et al. . A geriatric-anesthesiologic program to reduce acute confusional states in elderly patients treated for femoral neck fractures. J Am Geriatr Soc. 1991; 39(7): 655-62. PMid:2061530.

[8] Marcantonio ER, Flacker JM, Wright RJ, Resnick NM. Reducing delirium after hip fracture: a randomized trial. J Am Geriatr Soc. 2001; 49(5): 516-22. PMid:11380742. http://dx.doi.org/10. 1046/j.1532-5415.2001.49108.x

[9] Pretto M, Spirig R, Milisen K, DeGeest S, Regazzoni P, Hasemann W. Effects of an interdisciplinary nurse-led Delirium Prevention and Management Program (DPMP) on nursing workload: A pilot study Int J Nurs Stud. 2009; 46: 804-12. PMid:19249782. http://dx.doi.org/10.1016/j.ijnurstu.2009.01.015

[10] Tsang LF. Nurse' prediction prevention and management on postoperative delirium in geriatric patients with hip fracture: The development of a protocol to guide care. Int J Orthop Traum Nurs. 2014; 18(1): 23-34. http://dx.doi.org/10.1016/j.ijotn.2 013.06 .001

[11] Schoenfeld D. Statistical considerations for a parallel trial where the outcome is a measurement [Internet]. 2014 [cited 2013 Feb 4]. Available from: http://hedwig.mgh.harvard.edu/sampl e_size/js/js_parallel_quant.html

[12] National Clinical Guideline Centre. Delirium: diagnosis, prevention and management. Clinical Guideline 103. The National Institute for Health and Clinical Excellence [Internet]. 2010 [cited 2014 Jan
13]. Available from: http://www.nice.org.uk/guidance/cg1 03/resources/cg103-delirium-full-guideline3

[13] Tsang LF, Yiu WY, Kwok WH, Tse CC, Ng SW, Chu KK, et al. Development of an educational pamphlet on postoperative delirium management in older people receiving hip fracture surgery. Int J Orthop Traum Nurs. 2014; 18(3): 151-161. http://dx.doi.org/1 $0.1016 /$ j.ijotn.2013.10.001

[14] Neitzel J, Sendelbach S, Larson LR. Delirium in the orthopaedic patient. Orthop Nurs. 2007; 26(6): 354-65. PMid:18046209. http: //dx.doi.org/10.1097/01. NOR.0000300946.86708.bc

[15] Inouye SK, van Dyck CH, Alessi CA, Balkin S, Siegal AP, Horwitz RI. Clarifying Confusion: The Confusion Assessment Method: A New Method for Detection of Delirium. Ann Intern Med. 1990; 113: 941-8. PMid:2240918. http://dx.doi.org/10.7326/000 3-4819-113-12-941

[16] Zou Y, Cole MG, Primeau FJ, et al. Detection and diagnosis of delirium in the elderly: psychiatrist diagnosis, confusion assessment method, or consensus diagnosis? IPA. 1998; 10: 301-8.

[17] Inouye SK. Delirium in older persons. NEJM. 2006; 354: $1157-$ 65. PMid:16540616. http://dx.doi.org/10.1056/NEJMra052 321

[18] Fick DM. Delirium superimposed on dementia is pervasive and associated with restraint use among older adults residing in long-term care. Appl Nurs Res. 2011; 24: 171-8. PMid:20974072. http: //dx.doi.org/10.1016/j.apnr.2009.07.001

[19] Sanders RD, Pandharipande PP, Davidson AJ, Ma D, Maze M. Anticipating and managing postoperative delirium and cognitive decline in adults. BMJ. 2011; 343: d4331. PMid:21775401. http: //dx.doi.org/10.1136/bmj.d4331

[20] Maher AB, Meehan AJ, Hertz K, Hommel A, MacDonald V, O'Sullivan MP, et al. Acute nursing care of the older adult with fragility hip fracture: An international perspective (Part 1). Int J Orthop Traum Nurs. 2012; 16(4): 177-94. http://dx.doi .org/10. 1016/j.ijotn.2012.09.001

[21] Young J, Inouye SK. Delirium in older people. BMJ. 2007; 334: 842-6. PMid:17446616. http://dx.doi.org/10.1136/b $\mathrm{mj}$.39169.706574.AD

[22] Ohki T, Matsushima E, Shibuya M., Sunamori M. An evaluation strategy for the early detection of postoperative delirium. Psychiat Clin Neuros. 2006; 60: 277-82. PMid:16732742. http://dx.doi .org/10.1111/j.1440-1819.2006.01502.x

[23] British Geriatric Society. Guidelines for the prevention, diagnosis and management of delirium in older people in hospital [Internet]. 2006 Jan 2 [cited 2014 Jan 3]. Available from: http://www.bgs.org.uk/index.php/clinicalguides/17 0-clinguidedeliriumtreatment?showall=\&limitstart=

[24] Tsang LF, Yeung CH, Lam KB, Tse CC, Chu KK, Wong WS, et al. Developing a preventive protocol for postoperative delirium in Orthopaedic settings. Association of Maltese Orthopaedic Nurses: 3rd Int Orthop Nurs Conf. 2012. 